\title{
Evaluation of Residual Stresses in Carbon/Carbon Composites Components Joined to Copper before and after Pulse Electromagnetic Treatment
}

\author{
G. V. Stepanov, ${ }^{a}$ A. I. Babutskii, ${ }^{\text {a I. A. Mameev, }{ }^{a} \text { M. Ferraris, }{ }^{\text {b }} \text { V. Casalegno, }}$ \\ and M. Salvo ${ }^{b}$ \\ ${ }^{a}$ Pisarenko Institute of Problems of Strength, National Academy of Sciences of Ukraine, \\ Kiev, Ukraine \\ ${ }^{\mathrm{b}}$ Materials Science and Chemical Engineering Department, Politecnico di Torino, Torino, \\ Italy
}

УДК $539.3 ; 537.39$

\section{Оценка остаточных напряжений в соединении углеродный композит-медь до и после импульсной электромагнитной обработки}

\author{
Г. В. Степанов ${ }^{\mathrm{a}}$ А. И. Бабуцкий ${ }^{\mathrm{a}}$, И. А. Мамеев $^{\mathrm{a}}$, М. Феррарис ${ }^{\sigma}$, \\ В. Касалегно ${ }^{\sigma}$ М. Салвоб
}

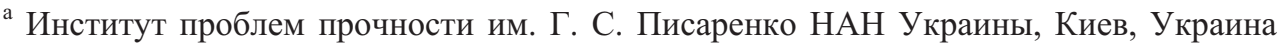

${ }^{\sigma}$ Туринский политехнический институт, Турин, Италия

Приведены результаты расчетно-экспериментальной оценки остаточных напряжений в компонентах, полученных соединением композита (углерод, упрочненный углеродными волокнами) с медью. Установлено, что импульсная электромагнитная обработка соединения уменьшает уровень остаточных напряжений.

Ключевые слова: соединение композит-медь, остаточные напряжения, импульсный электрический ток.

Introduction. The influence of tensile residual stresses (RS) on thermal and mechanical fatigue of structural elements is well known [1, 2]. In accordance with numerous experimental data, a pulsed electric current treatment (PECT) considerably influences stress relaxation in metals under active loading (elongation) [3-5], as well as the RS of type 1 and type 2 originated after metal-shaping [6]; some data about pulse electromagnetic treatment for reduction of welding RS are available [7].

Pulse electric current treatment has been proposed by authors as a simple technology for reducing RS in joined metal-composite components [8]. The PECT is cost-effective; the process can be done at room temperature by using simple equipments. In [8], the results of experimental evaluation of PECT influence on the reduction of RS in composite-to-copper joint with a flat tile design was discussed.

(C) G. V. STEPANOV, A. I. BABUtSkiI, I. A. MAMEEV, M. FERRARIS, V. CASAlEGNO, M. SALVO, 
This paper presents the results of an experimental determination of RS evolution during pulse electro-magnetic field (PEMF) in a composite-to-copper joint produced by inserting a copper alloy tube inside a block of carbon fiber reinforced carbon composite (CFC). The joined component has a monoblock type design to be used for the International thermonuclear experimental reactor (ITER). The ITER design comprises the divertor, which is the part of the fusion reactor with the highest thermal load. The heat transfer in the divertor occurs between the plasma facing components (PFCs) and the heat sink. In some parts of the divertor the PFC that acts as protective material (armor) for the reactor structure is carbon fiber reinforced carbon composite and the heat sink is made of $\mathrm{CuCrZr}$ alloy. The $\mathrm{CFC}$ is joined to the heat sink by the introduction of an intermediate ductile layer, to reduce the high stresses arising from large mismatch of coefficients of thermal expansion (CTE) between the composite and the copper alloy $\left[C T E_{\mathrm{CFC}}=\right.$ $=(0.7-1.3) \cdot 10^{-6} \mathrm{~K}^{-1}$ and $\left.C T E_{\mathrm{CuCrZr}}=(16-17) \cdot 10^{-6} \mathrm{~K}^{-1}\right]$ [8]. The compliant layer (about $1 \mathrm{~mm}$ thick) is a oxygen-free high conductivity (OFHC) copper.

The RS at the interfaces can limit the performance of the component during high heat flux (HHF) tests and reduce the life-time of the heat-sink/armor joint. As a consequence, the study of $\mathrm{RS}$ at the metal/ceramic interface and their reduction is mandatory to improve the behavior in service of the component. Two geometric configurations have been studied for the armour/heat sink component: flat-tile and monoblock [9, 10]. The second one is the reference geometry for ITER and comprises a heat sink shaped like a pipe passing through a hole in CFC tiles. Because of its design the monoblock seems to be affected by higher thermal stresses during manufacturing process than flat-tile, as discussed in [9].

To investigate RS in the composite joined to copper and determine PEMF influence on change of RS, several monoblock specimens were manufactured by two different techniques (monoblock types 1 and 2) for the present paper. The thermal induced stresses in the specimens have been calculated by considering the maximum temperature reached by each specimen during its preparation (brazing $T=970^{\circ} \mathrm{C}$ in case of monoblock type 1 and $T=1200^{\circ} \mathrm{C}$ in case of monoblock type 2).

Composite-Copper Monoblock Manufacturing. In general the monoblock is obtained by drilling blocks of $\mathrm{CFC}$ into which a $\mathrm{CuCrZr}$ tube is inserted and joined; a thin layer (about $1 \mathrm{~mm}$ ) of pure copper is required between carbon composites and copper alloy, in order to relax high joint interface stress. In the present investigation, two types of monoblocks were manufactured by using CFC blocks and pure copper tubes instead of complete monoblocks with $\mathrm{CFC} /$ pure $\mathrm{Cu}$ and $\mathrm{CuCrZr}$ pipes.

Monoblocks of Type 1. The $\mathrm{CFC}-\mathrm{Cu}$ monoblock specimens (Fig. 1) were manufactured by using $\mathrm{Cu}$ pipes $(0.75 \mathrm{~mm}$ thick and outer diameter of $8 \mathrm{~mm})$ inserted in CFC blocks of $15 \times 15 \mathrm{~mm}$ cross section and $13 \mathrm{~mm}$ length. CFC NB31 manufactured by SNECMA Propulsion Solide (France) via European Fusion Development Agreement, OFHC copper pipe from Goodfellow (USA) were used. The process foresees the CFC surface modification through $\mathrm{Cr}$ and then brazing with a commercial non-active brazing alloy, the $\mathrm{Gemco}^{\circledR}[87.75 \mathrm{wt} . \% \mathrm{Cu}, 12 \mathrm{wt} . \%$ Ge and 0.25 wt.\% Ni; Wesgo Metals (USA)]. The modified surface is the inner hole in the CFC; the modification process consists of chromium powder deposited 
by slurry technique on the $\mathrm{CFC}$ and then a thermal treatment $\left(T=1300^{\circ} \mathrm{C} ; 1 \mathrm{~h}\right.$; in vacuum) to obtain a continuous layer of chromium carbides through solid state reaction $\left(\mathrm{Cr}_{23} \mathrm{C}_{6}, \mathrm{Cr}_{7} \mathrm{C}_{3}\right)$ [11]; this layer was proved to be wettable by non-active brazing alloy as Gemco alloy [12]. Three foils of Gemco alloy (foil thickness $60 \mu \mathrm{m}$ ) were used to join $\mathrm{CFC}$ to the $\mathrm{Cu}$ pipe and $\mathrm{Cu}$ to $\mathrm{CuCrZr}$ (pipe); the components used for the experimental work comprise only the $\mathrm{CFC}$ tile joined to pure $\mathrm{Cu}$ pipe. The joining process was called "one-step brazing" process. More details on this process are given in [13]. Microstructural investigations, as well as shear tests, were performed to investigate the mechanical strength and thermal shock resistance of the joints. Results are reported elsewhere [14].

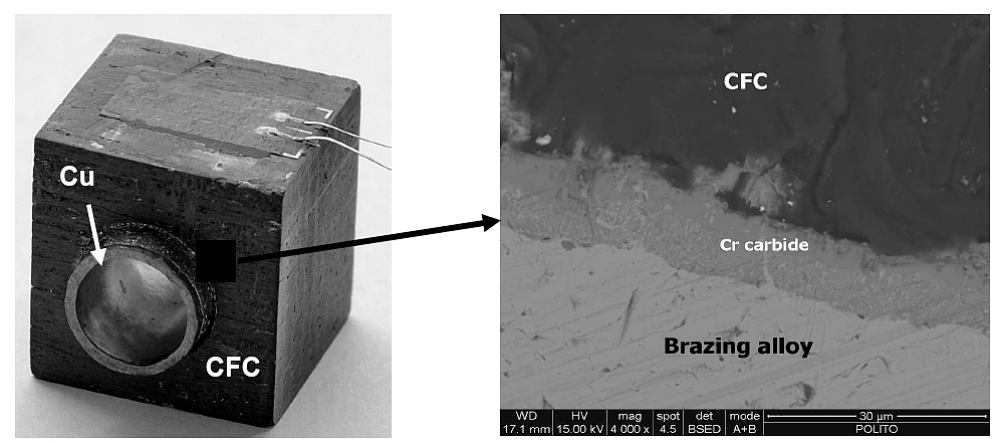

Fig. 1. CFC-Cu monoblock of type 1 with glued strain gauge (on the left). SEM image of the cross section of a $\mathrm{CFC}-\mathrm{Cu}$ joint: the chromium carbide modified $\mathrm{CFC}$-brazing alloy interface (on the right).

Morphological analysis of joined specimens shows crack-free interfaces and continuous bonding at metal-ceramic interface (Fig. 1). The Cr-carbide coating on CFC surface is clearly visible in the resulting microstructure and it allows a good wettability with the brazing alloy.

Monoblocks of Type 2. The second type of $\mathrm{CFC}-\mathrm{Cu}$ monoblock specimens (Fig. 2) was made using a different process. The CFC NB31 composite with $26 \times 26 \mathrm{~mm}$ cross section was drilled to obtain the hole with a diameter of $18 \mathrm{~mm}$. The as-prepared specimens were submitted to surface modification on the inner side of the hole as described above. The OFHC copper was cast onto the Cr-modified surface. The main problem of casting pure copper into a not-flat geometry is the significant shrinkage of $\mathrm{Cu}$ when solidification occurs; as a consequence stresses at $\mathrm{CFC}-\mathrm{Cu}$ interface increase drastically.

In order to reduce thermal stress by counterbalancing the copper shrinkage, a graphite cylinder was put inside the hole before $\mathrm{Cu}$ casting; copper was positioned in a form of foil in the annulus; heat treatment was performed in tubular furnace at temperature above copper melting point $T_{\text {melting }}\left(1200^{\circ} \mathrm{C}\right.$ for $20 \mathrm{~min}$ in argon atmosphere). Then the graphite cylinder was removed by machining and the monoblock was cut into several pieces of $4 \mathrm{~mm}$ thickness for further investigation of the RS. Microstructural analysis of obtained specimens shows crack-free interface and good continuous bonding at metal-composite interface (Fig. 2).

PEMF Treatment and Evaluation of the RS Changes in the Monoblocks of Type 1. In [8], the $\mathrm{CFC}-\mathrm{Cu}$ flat-tile specimens were manufactured according to method described for type 2, but with a flat geometry, which is assumed to be 
different in terms of RS from the curved one. In [8], the direct current (PECT) was used for investigation of the RS relaxation. In the present work, a treatment of the monoblocks of type 1 was done using induced (eddy) currents originating from PEMF. Four monoblocks of type 1 (two as-prepared and two treated by PEMF) have been tested.

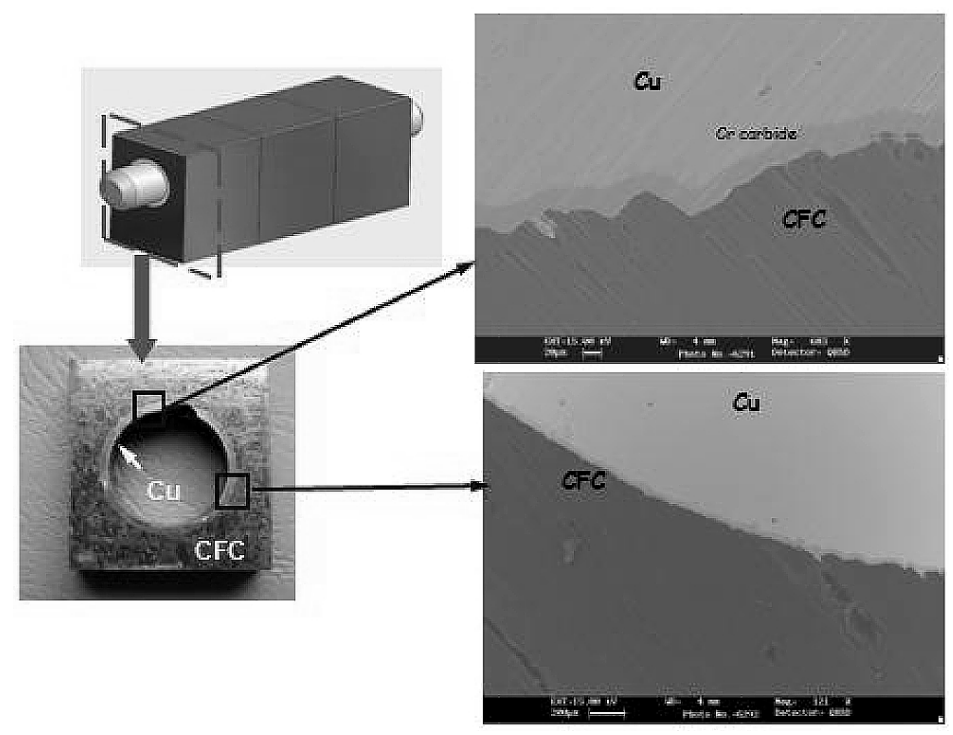

Fig. 2. $\mathrm{CFC}-\mathrm{Cu}$ monoblock of type 2 (on the left). SEM image of the cross section of a $\mathrm{CFC}-\mathrm{Cu}$ joint: the chromium carbide modified $\mathrm{CFC}-$ cast $\mathrm{Cu}$ interface (on the right).

Before the treatment a cylindrical steel rod was inserted into a hole of the monoblock and then a pulsed current was passed through the rod (Fig. 3). As a result, pulsed magnetic field of the passing current induces the eddy currents in $\mathrm{Cu}$-layer of the monoblock. The treatment was performed by using pulse electric current generator consisting of high voltage power supply, capacitor banks and discharge switch; registration of the pulse electric current parameters was realized using the Rogovsky coil, high frequency A/D converter and PC where data were stored and processed [15]. Registered "current-time" dependence is presented in Fig. 4. Two short sequential pulses of the electric current with the maximum amplitude of $I_{\max } \approx 80 \mathrm{kA}$ were passed through the steel rod.

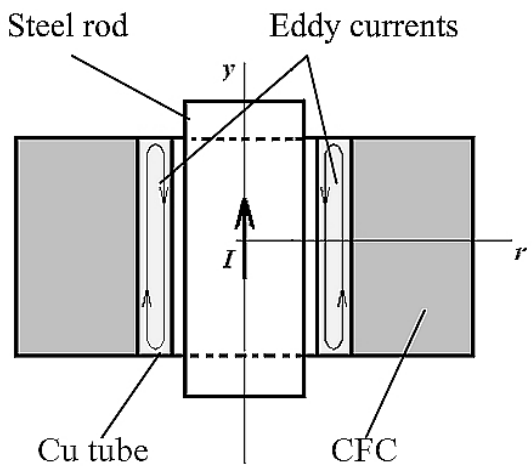

Fig. 3. The scheme of PEMF treatment of the monoblock specimens. 


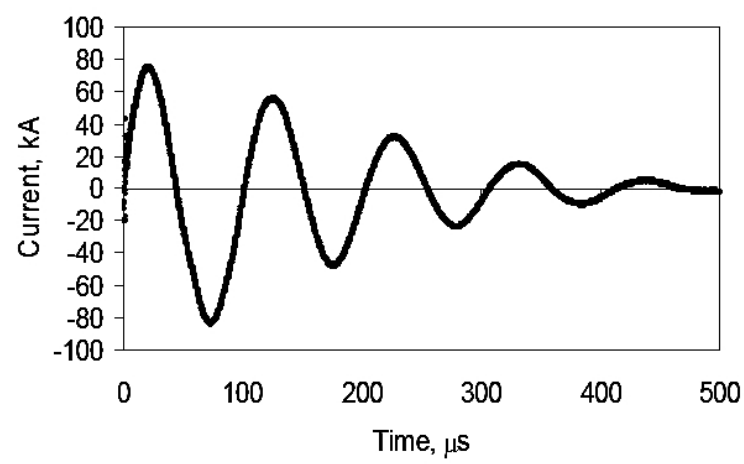

Fig. 4. Registered pulsed current passing through the cylindrical $\operatorname{rod}(U=4 \mathrm{kV}, C=600 \mu \mathrm{F})$.

Influence of PEMF treatment on the RS in the $\mathrm{CFC}-\mathrm{Cu}$ joints was investigated by comparison of specimens' behavior before and after the treatment. As in [8], the destructive method for determination of changes in RS distribution was chosen at the fulfillment of this investigation. According to the method, controlled step-bystep removal or slitting (successive extension of a slot) of the material from the one side and registration of corresponding elastic deformations on the other side is used. The measured deformation at a given point in the material depends on all the stresses within the removed material [16]. The simplest way to determine such relationship is using the finite element method (FEM) simulation. In our case, changes of RS distribution in CFC-layer before and after PEMF treatment can be determined by analyzing the differences in dependences of strain changes under step-by-step slitting of CFC and congruous measuring of the strains at the adjacent face (Fig. 5).

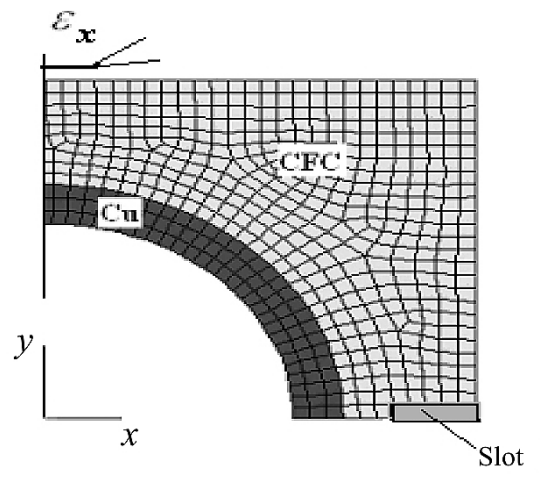

Fig. 5. Finite element scheme of $\mathrm{CFC}-\mathrm{Cu}$ monoblock used for FEM simulation.

One 5-mm strain gauge was glued before the tests on the CFC face of each monoblock (Fig. 1). Data on gauge strains and their signal variation under slitting (slot width $B=1 \mathrm{~mm}$ ) were obtained using commercial ICP CON I-7016P module. Using ICP CON I-7520 (RS 232) module, the above data were transferred into a PC.

Experimental data and simulation results were used to evaluate changes of RS in $\mathrm{CFC}-\mathrm{Cu}$ monoblocks caused by PEMF treatment. It includes slitting, as well as FEM simulation based on ANSYS-ED package. Finite element scheme used under modeling of formation of the RS, as well as slitting of monoblocks, is presented in 
Fig. 5; real sizes of the monoblock are used. Calculations were carried out assuming that mechanical and thermo-physical properties of the CFC and copper (yield stress, the Young modulus, Poisson's ratio, density, thermal expansion, specific heat, thermal conductivity) change linearly depending on temperature according to data mentioned in earlier work [8].

Simulation of RS formation processes at the brazing temperature was performed. Then the stress-strain state changes under slitting of CFC-layer were also simulated.

The stress-strain state of the specimen was calculated at plane deformation condition for zero initial stresses. The temperature was taken as $1000^{\circ} \mathrm{C}$, then cooling under convection heat exchange with the environment through an external layer of CFC was simulated.

In Fig. 6, the distribution of the RS along $x$-axis (axis orientation is given in Fig. 5) is presented; from equilibrium condition the average tensile stress $\sigma_{\mathrm{Cu}}$ in the $\mathrm{Cu}$-layer having a thickness of $b_{\mathrm{Cu}}$ and the average compressive stress $\sigma_{\mathrm{CFC}}$ in the CFC-layer having a thickness of $b_{\mathrm{CFC}}$ are interrelated:

$$
\sigma_{\mathrm{CFC}} b_{\mathrm{CFC}}=\sigma_{\mathrm{Cu}} b_{\mathrm{Cu}} \text {. }
$$

According to the calculation results, the average compressive stress $\sigma_{\mathrm{CFC}}$ is about $13 \mathrm{MPa}$, the average tensile stress $\sigma_{\mathrm{Cu}}$ is about $55 \mathrm{MPa}$ and Eq. (1) is valid. Noteworthy is that distribution of residual stresses $\sigma_{y}$ in $\mathrm{Cu}$ - and CFC-layers in circumferential direction is essentially nonuniform due to the rectangular contour of the CFC-layer.

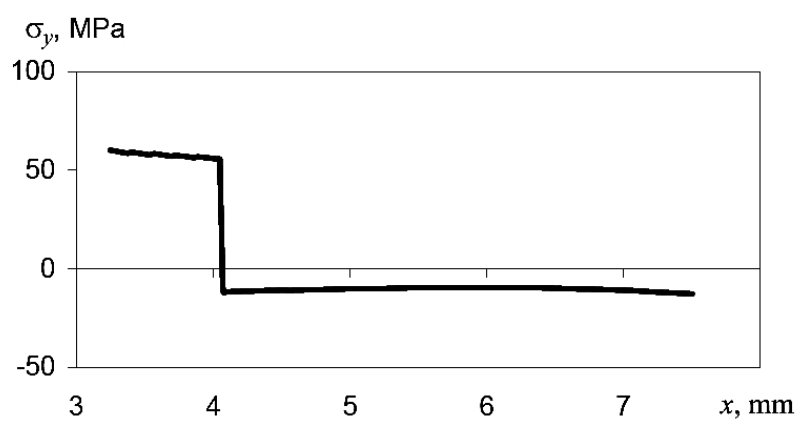

Fig. 6. Simulation of the distribution of residual stresses $\sigma_{y}$ along the symmetry axis $x$ in the monoblock of type 1 after brazing and cooling.

The second part of simulation involved step-by-step slitting of CFC-layer with an increment of $1 \mathrm{~mm}$. Slitting was simulated by eliminating the finite elements in the CFC part of the FEM model (Fig. 5). Elastic behavior of materials under slitting is supposed. Calculated strains on the face adjacent to the slot and corresponding to the strain gauge location are presented in Fig. 7 by a solid line.

As it follows from the results of numerical simulation, the slitting of CFC with $1 \mathrm{~mm}$ width in the middle of the face causes a reduction of compressive stresses on the adjacent face (below the gauge location, Fig. 5). Calculated dependence of the change of strains against the slot depth in the measuring point agree quite well with experimental data obtained using strain gauge for mono- 


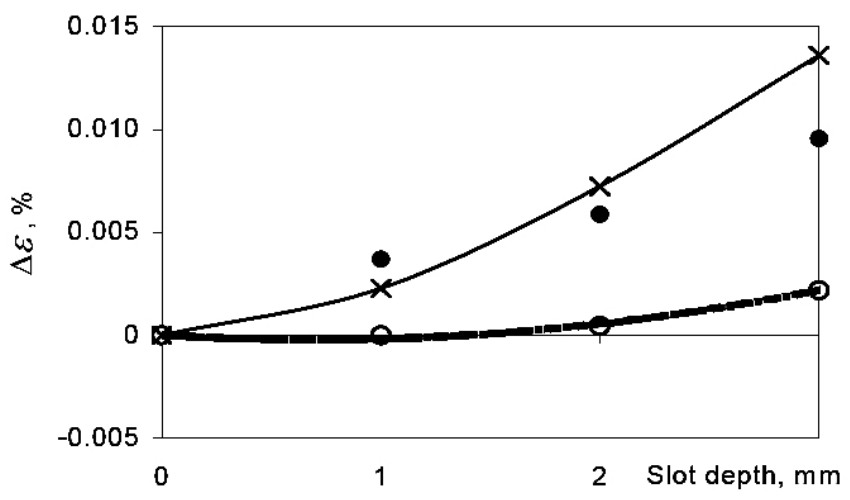

Fig. 7. Strain variation below the gauge at slitting with 1-mm width of as-manufactured (without PEMF treatment) monoblock of type 1 (simulation - solid line and experiment - solid symbols) and monoblock type 1 after PEMF treatment (open symbols). Experimental points are the data averaging for two pairs (untreated and treated by PEMF) of monoblocks.

blocks in the initial condition (without PEMF treatment), Fig. 7. This is an evidence of a correctness of the model and properties of the materials used under the simulation.

According to the experimental data given in Fig. 7, the induced current causes a reduction of compressive strains of $77 \%$. It means that compressive stresses in CFC-layer, as well as tensile stresses in Cu-layer [in compliance with Eq. (1)], are reduced in the same proportion after the treatment. Thus, the PEMF treatment with used current parameters causes a substantial reduction of RS in the monoblock.

Kinetics of this change is a result of some effects: an action of ponderomotive forces within passing of pulsed current; a thermal expansion caused by the Joule heating; and a drop of resistance to deformation of $\mathrm{Cu}$ caused by an nonthermal effect of induced pulsed current (electroplastic effect) [3-5].

Numerical modeling of PEMF treatment of the monoblock without RS was undertaken to estimate the effects of some of the above-mentioned factors. Main calculations were fulfilled using a simplified model of the monoblock with the cylindrical steel rod inserted into the monoblock CFC tile holes (plane axisymmetric model with $15 \mathrm{~mm}$ outer diameter of CFC-layer). Additionally, a 3D model of monoblock with a rod inserted into the tile holes (Fig. 3) was used in the simulation to clarify the features of distribution of eddy currents under the PEMF treatment.

Variation of the current in the cylindrical rod under the treatment was taken in a form of decaying sinusoid: $I(t)=I_{0} \exp (-t / \tau) \sin (2 \pi t / \tau)\left(I_{0}\right.$ is a nominal amplitude of the passing current and $\tau=100 \mu$ s is a cycle of variation). Value of current $I$ for registered current's pattern (Fig. 4) was defined using the maximum of registered amplitude in accordance to an expression $I_{0} \approx 1.282 I_{\max }\left(I_{\max }=80 \mathrm{kA}\right)$.

According to results of the $3 \mathrm{D}$ simulation, passage of the pulsed current through the central rod induces eddy currents in the copper tube. These are oriented along the contour of cross section of the copper tube (Fig. 3). The amplitude of a full current in the copper corresponds to the current amplitude in the central rod. On the other hand, density of the eddy currents near the inner surface of the copper tube is higher than that near its outer surface and much higher than 
the maximum current density in the steel rod. The eddy currents in CFC-layer are much lower than in Cu-layer, and their effect is neglected.

Variation of the circumferential stresses in the monoblock follows from results of the simulation based on a plane axisymmetric model of the monoblock accounting effects of ponderomotive forces and heating (Fig. 8).

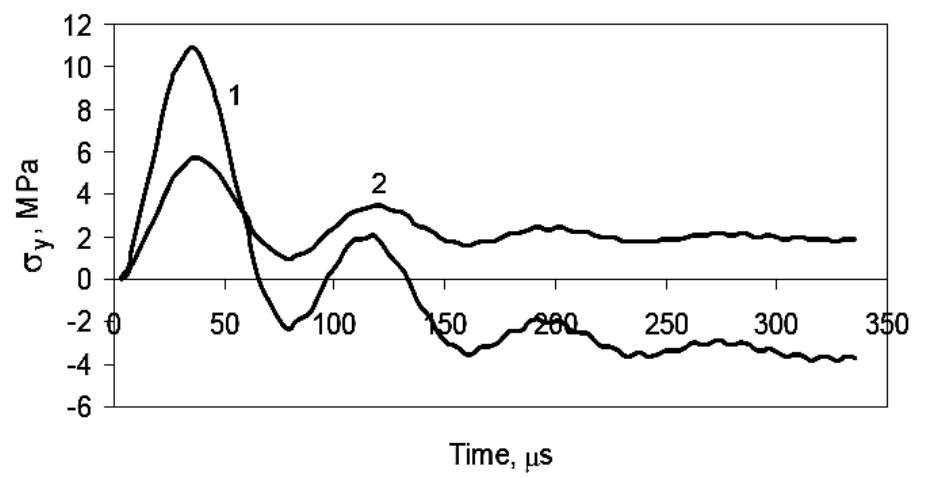

Fig. 8. Time variation of circumferential stresses $\sigma_{y}$ near $\mathrm{CFC}-\mathrm{Cu}$ interface: (1) $\mathrm{Cu}$; (2) $\mathrm{CFC}$.

At the starting stage (near $\tau / 2$ ) the circumferential tensile stresses $\sigma_{y} \approx 11 \mathrm{MPa}$ act in $\mathrm{Cu}$-layer as a result of its radial expansion caused by the ponderomotive forces. In a subsequent period, the compressive stresses originated from an increase of the temperature in $\mathrm{Cu}$-layer caused by the Joule heating (about $5^{\circ} \mathrm{C}$ ) are retained there. They act up to complete cooling and then they disappear. Thus, effects of the ponderomotive forces and the Joule heating cannot influence substantially the RS redistribution in the monoblock.

Taking into account the lack of effects from ponderomotive forces and the Joule heating on the change of RS (the last was stated in the experiments), it should be concluded that the main contribution to stress reduction by the PEMF treatment is due to the athermal effect of induced pulsed current (electroplastic effect, [3-5]). The obtained results are comparable with those reported in [8]; the effect of pulse electric treatment causes a decrease in stress distribution.

Evaluation of the RS Changes in the Monoblocks of Type 2. As for the monoblocks of type 1, simulation of the RS formation during the manufacturing stage was performed for monoblocks of type 2: the model included the outer CFC-layer with dimensions of $26 \times 26 \mathrm{~mm}$ and central hole of $18 \mathrm{~mm}$, the tubular $\mathrm{Cu}$-layer with outer diameter of $18 \mathrm{~mm}$ and wall thickness of $1.5 \mathrm{~mm}$ and additional cylindrical element with outer diameter of $15 \mathrm{~mm}$ inserted in the monoblock. The properties of the cylinder were the same as for the outer CFC-layer.

The stress-strain state of the specimen was calculated for zero initial stresses. It was specified that the initial temperature of the materials was assumed to be $1000^{\circ} \mathrm{C}$. Then cooling under convection heat exchange with an environment through the external contour of the outer CFC-layer was modeled. After that, the cutoff of the inner cylinder was modeled. The results of the modeling showed that final RS distribution in the monoblock of type 2 is similar to the distribution presented in Fig. 6 for monoblocks of type 1, but the average compressive stress 
is about $12 \mathrm{MPa}$ and the average tensile stress $\sigma_{\mathrm{Cu}}$ is about $32 \mathrm{MPa}$, thus slightly lower than for type 1 .

To validate the correctness of the model and properties of the materials used at the simulation of monoblock of type 2, the modeling of step-by-step slitting of CFC-layer of the monoblock with an increment of $1 \mathrm{~mm}$ was done (by analogy with monoblock of type 1). The modeling was carried out at plane stress condition for as-manufactured (without PEMF treatment) monoblock (type 2). Calculated dependence of the strain change below the gauge at slitting, as well as experimental data for monoblock of type 2 with 4-mm thickness, are presented in Fig. 9, which is comparable to Fig. 7 for type 1, since in this case it is also referred to "as-received" monoblock, not treated by PEMF.

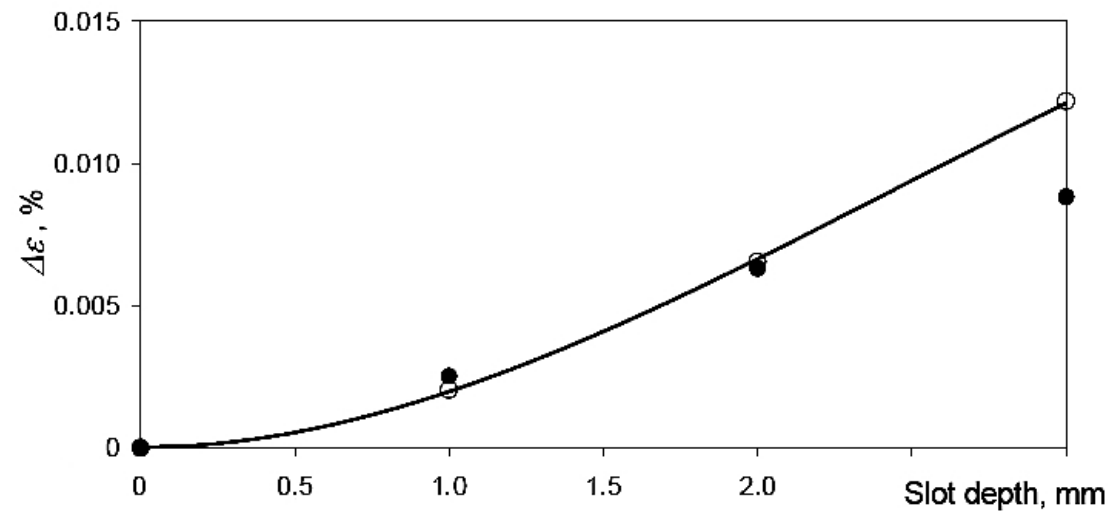

Fig. 9. Strain variation below the gauge at slitting with $1-\mathrm{mm}$ width of as-manufactured (without PEMF treatment) monoblock of type 2 (modeling - open symbols and experiment - solid symbols). One untreated monoblock of type 2 was used for the experimental work.

The experimental data were obtained by using the same technique as above for the monoblock of type 1. Satisfactory data fitting testifies a correctness of the model and properties of the materials used under the simulation.

By comparing Fig. 7 and Fig. 9 it can be seen that the two manufacturing methods (type 1 and type 2) do not differ in terms of RS in CFC layer.

In order to investigate if the RS generated during manufacturing of monoblocks of type 2 (tensile circumferential stresses in the $\mathrm{Cu}$-layer and compressive circumferential stresses in the CFC-layer) can influence their stress state under operational thermal shock $\left(T=1000^{\circ} \mathrm{C}\right)$, the results of qualitative evaluation of thermal shock based on numerical simulation are presented below.

The model corresponding to the plane strain condition was used. Thermal loading of the monoblock simulating the operation conditions was determined as follows: only the outer surfaces of $\mathrm{CFC}$ were heated $\left(T=1000^{\circ} \mathrm{C}\right)$ and calculations were carried out accepting the same mechanical and thermo-physical properties of the materials as above in case of monoblocks of type 1.

Thermal loading of the monoblock of type 2 which simulated the operational thermal shock was determined as follows: the outer surfaces of CFC were heated by thermal shock up to $1000^{\circ} \mathrm{C}$; the inner surface of $\mathrm{Cu}$-tube was held at room temperature. Numerical modeling was done at two variants of initial conditions: 
(1) the RS obtained at modeling of the manufacturing stage for the monoblocks of type 2 were used;

(2) zero initial stresses (absence of any RS) in the monoblock were used.

The results of modeling are presented in Fig. 10 and they show the difference in stress state of monoblock of type 2 depending on initial conditions (with or without RS) under simulated operational thermal shock: at $\mathrm{CFC}-\mathrm{Cu}$ interface the tensile stresses in CFC for monoblock with the RS are about $24 \mathrm{MPa}$ and without the RS are about $19 \mathrm{MPa}(20 \%$ lower). As it follows from distributions of stresses (Fig. 10), the total stress intensity of monoblock without RS is also lower; the trend of this curve is different from that in Fig. 6, since these data refer to monoblock under operational thermal shock.

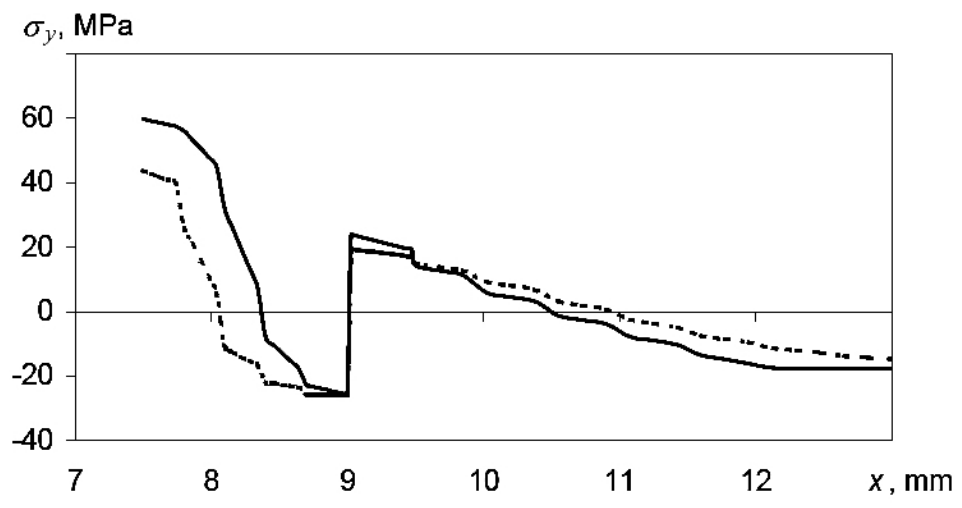

Fig. 10. Distribution of $\sigma_{y}$ stresses along the symmetry axis $x$ in the monoblock of type 2 under operational thermal shock: solid line - monoblock with RS, dashed line - monoblock without RS.

Conclusions. A qualitative description of RS induced by manufacturing route used for the monoblocks of type 1 (the one-step process, brazing technique) and type 2 (casting technique) has been performed. According to results of the modeling, the final RS distribution in the monoblock of type 2 is comparable with the distribution for monoblocks of type 1.

The influence of PEMF treatment on RS in the monoblock of type 1 has been studied. Previous investigation of direct passage of pulsed current through the flat tile $\mathrm{CFC}-\mathrm{Cu}$ joint [8], as well as present results of PEMF treatment of the $\mathrm{CFC}-\mathrm{Cu}$ monoblocks, confirm a substantial elimination of the RS originated in the joints at the manufacturing stage.

Furthermore, preliminary studies on stress state on thermally shocked monoblock of type 2 with RS (in the as-manufactured conditions) and without RS have been carried out. Elimination of the RS in monoblocks of type 2 results in reduction of the total stress intensity of the monoblocks under operation and it can increase their durability and lifetime. Additional work is required to compare the manufacturing route used for monoblocks of types 1 and 2 in terms of RS after simulated thermal shock.

Further investigations should address microstructural changes in CFC-tocopper joint after the treatment performed, as well as confirmation of PEMF treatment effect on durability and life of monoblocks under cyclic thermal loading. 
This work was supported in part by the EU Network of Excellence project Knowledge-based Multicomponent Materials for Durable and Safe Performance (KMM-NoE) under the contract No. NMP3-CT-2004-502243.

\section{Резюме}

Наведено результати розрахунково-експериментальної оцінки залишкових напружень у компонентах, що отримані з’єднуванням композита (вуглець, зміцнений вуглецевими волокнами) з міддю. Установлено, що імпульсна електромагнітна обробка з'єднання зменшує рівень залишкових напружень.

1. Y. C. Lin and S. C. Chen, "Effect of residual stress on thermal fatigue in a type 420 martensitic stainless steel weldment," J. Mater. Proc. Technol., 138, 22-27 (2003).

2. M. N. James, D. J. Hughes, Z. Chen, et el., "Residual stresses and fatigue performance," Eng. Failure Anal., 14, 384-395 (2007).

3. Yu. V. Baranov, O. V. Troitskii, Yu. S. Avraamov, and A. D. Shlyapin, Physical Grounds of Electric Pulse and Electric Current/Plastic Treatments and New Materials [in Russian], MGIU, Moscow (2001).

4. A. F. Sprecher, S. L. Mannan, and H. Conrad, "On the mechanisms for the electroplastic effects in metals," Acta Metal., 34, No. 7, 1145-1162 (1986).

5. G. V. Stepanov, A. I. Babutskii, I. A. Mameev, and A. N. Olisov, "Analysis of pulse current-induced tensile stress relaxation," Strength Mater., 38, No. 1, 84-91 (2006).

6. V. A. Boguslaev, A. I. Dolmatov, P. D. Zhemanyuk, et al., Life Prolongation of Gas Turbine Disk Titanium Alloy Parts [in Russian], Zaporozhye (2000).

7. A. D. Glinberg, N. A. Karandashev, A. F. Krutin, and E. N. Sidorenkov, "Practics and perspectives of application of magnetic-pulse treatment of metals," in: Proc. Int. Conf. on Action of Electromagnetic Fields and Electric Current on Metals (October 21-24, 2003), Moscow (2003), pp. 55-57.

8. G. V. Stepanov, A. I. Babutskii, I. A. Mameev, et al., "Experimental evaluation of pulse electric current effect on residual stresses in composite-tocopper joints," Strength Mater., 40, No. 4, 452-457 (2008).

9. M. Merola and G. Vieider, "On the use of flat tile armour in high heat flux components," J. Nucl. Mater., 258-263, 672-676 (1998).

10. R. Tivey, M. Akiba, D. Driemeyer, et al., "ITER R\&D: vacuum vessel and in-vessel components: divertor cassette," Fusion Eng. Des., 55, 219-229 (2001).

11. P. Appendino, M. Ferraris, V. Casalegno, et al., "Proposal for a new technique to join CFC composites to copper," J. Nucl. Mater., 358, 102-107 (2006).

12. M. Ferraris, V. Casalegno, M. Salvo, Process to Join Carbon Based Materials to Metals and Its Applications, Patent WO2005/037734, Politecnico di Torino (2005). 
13. M. Salvo, V. Casalegno, S. Rizzo, et al., "One-step brazing process to join CFC composites to copper and copper alloy," J. Nucl. Mater., 374, 69-74 (2008).

14. V. Casalegno, M. Salvo, S. Murdaca, and M. Ferraris, "One-step brazing process for CFC monoblock joints and mechanical testing," J. Nucl. Mater., 393, 300-305 (2009).

15. G. V. Stepanov, A. I. Babutskii, I. A. Mameev, "High-density pulse currentinduced unsteady stress-strain state in a long rod," Strength Mater., 36, No. 4, 377-381(2004).

16. G. S. Schajer and M. B. Prime, "Use of inverse solutions for residual stress measurement," J. Eng. Mater. Technol., 128, No. 3, 375-382 (2006).

Received 17. 11. 2010 